\title{
REMARKS ON ADDITION PROCESSES OF POSITIVE FLOATING-POINT NUMBERS
}

1. This short note contains a proof of the following theorem:

The minimum of the upper bound of the absolute rounding error of a sum of positive floating-point numbers is attained for the algorithm of summation which in section 2 is called the algorithm $A L N$.

2. Paper [3] has dealt with the analysis of summation algorithms for the sum $A=a_{1}+a_{2}+\ldots+a_{n}$ of positive binary floating-point numbers to obtain an algorithm giving the sum $A$ with a minimal error. There were considered the following summation sequences for the sum $A$ :

the NS-sequence $\left(\ldots\left(\left(a_{1}+a_{2}\right)+a_{3}\right)+\ldots+a_{n}\right)$ and

the $\mathrm{ALN}$-sequence obtained by the following operations:

Add the two least numbers and insert the result among the remaining ones. Repeat this step $n-1$ times.

The main theorem of paper [3] states that if all exponents of the numbers $a_{1}, a_{2}, \ldots, a_{n}$ are different, then the addition of these numbers according to the summation sequence $A L N$ causes a minimal truncation error.

Next, it is assumed that there exists a constant $d$ such that the rounding error $a(a+b)$ of the sum $a+b$ is not greater than $d(a+b)$, i.e.

$$
\alpha(a+b) \leqslant d(a+\grave{b}) \text {. }
$$

Hence, for the NS-sequence of summation we have

$$
\alpha(A) \leqslant d\left[(n-1) a_{1}+\sum_{i=2}^{n}(n-i+1) a_{i}\right]
$$

and it is easy to see that this upper bound is minimal for a non-decreasing sequence $a_{1}, a_{2}, \ldots, a_{n}$.

Now we prove that the minimum of the upper bound of the absolute rounding error of the sum $A$ is attained by the ALN-sequence of summation. Binary trees (see [1] and [2]) will be used in the proof. 
Every way of computation of the sum $A$ can be represented by a binary tree with $n$ terminal nodes which correspond to the numbers $a_{1}, a_{2}, \ldots, a_{n}$ and with $n-1$ internal nodes which correspond to the summing operation. For example, the binary tree for the NS-sequence of summation is the following:

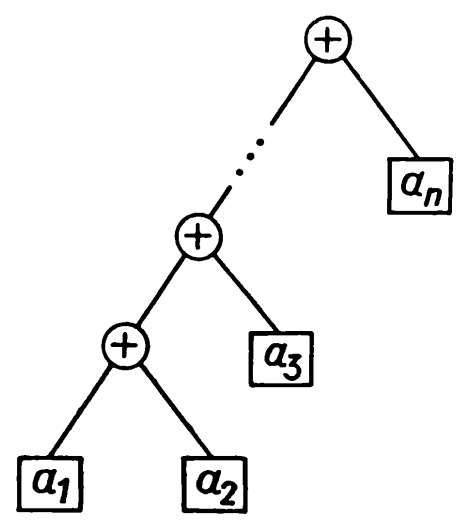

Let $l_{i}(i=1,2, \ldots, n)$ denote the length of the path (the number of tree arcs) from the terminal node $i$ to the root of the tree. For the NS-sequence of summation we have $l_{1}=n-1, \quad l_{i}=n-i+1 \quad(i=$ $=2,3, \ldots, n)$. It is easy to see that the maximal error for an arbitrary way of computation of the sum $A$ is equal to

$$
\sum_{i=1}^{n} l_{i} a_{i} .
$$

Hence, the minimization of the maximal error of the sum $A$ is equivalent to the minimization of the sum (1) over the sequences $l=\left\{l_{1}, l_{2}, \ldots, l_{n}\right\}$ which correspond to binary trees with $n$ terminal nodes. (Paper [1] contains the conditions which must be fulfilled by the sequence $l$.) The solution of this problem is well known ([1] and [2]). The sum (1) is minimized by the sequence $l^{*}$ which corresponds to Huffman's tree and, in turn, to the ALN-sequence of summation.

\section{References}

[1] T. C. Hu and A. C. Tucker, Optimal computer search tree and variable-length alphabetical codes, SIAM J. Appl. Math. 21 (1971), p. 514-532.

[2] D. E. Knuth, The art of computer programming, Vol. 1, Addison-Wesley, New York 1968, p. $399-415$.

[3] A. Szurman, On the minimum error in addition processes of positive floating-point numbers, Zastosow. Matem. 13 (1973), p. 351 -366.

DEPT. OF NUMERICAL METHODS

UNIVERSITY OF WROCEAW

50-384 WROCEAW

Received on 20.7. 1973 
M. M. SYSLO (Wroclaw)

UWAGI O SUMOWANIU CIĄGU ZMIENNOPOZYCYJNYCH LICZB DODATNICH

ST RWSZCZENIE

W notce przedstawiony jest bardzo prosty dowód twierdzenia, że minimum maksymalnego błędu zaokrąglenia sumy dodatnich liczb zmiennopozycyjnych jest osiągnięte dla kolejności ALN obliczania sumy. 